\title{
EDITORIAL
}

\section{Women-centred abortion care: Legitimising a disenfranchised aspect of healthcare}

\section{Te mahi whakatahe hāngai ki te wahine: Te whakaahua i te reo o tētahi wāhanga wahangū o te taurima hauora}

\author{
Chris Hannah, RN, RM, BA, MPH, MCouns, Clinical Manager, Taiarawhiti DHB, Gisborne, NZ \\ Catherine Cook, RN, RM, PG Cert TT, MCouns, PhD, Senior Lecturer, School of Nursing, Massey University, Albany, NZ \\ Tiziana Manea, RN, RM, MA, MCouns, Clinical Nurse Specialist, Taiarawhiti DHB, Gisborne, NZ
}

In her editorial, Helen Rook (2018) drew our collective attention to the importance of nurses having the moral courage to speak up about contentious issues, heeding the International Council of Nurses latest campaign for us to have a voice. In this editorial, the authors, all with years immersed in women's health service delivery and/or research, respond to this call, as we draw attention to the significance of a nursing and midwifery voice in the area of women's unplanned pregnancy and abortion care. This sensitive and controversial area of care to date has been primarily medically driven. We offer a vision of nursing and midwifery-led care, and a women-centred approach focused on women's lived experience - what has been called a provoice approach (Manninen, 2013) - where the aim is for women's experiences not to get lost in the political and philosophical 'noise' of pro and antiabortion debates.

Since 1893, we in Aotearoa New Zealand have led the way internationally in terms of women's rights. We take women's rights to self-determination as a given. We take women's rights to healthcare as a given. We understand our duty of care as nurses and

Hannah, C., Cook, C., \& Manea, T. (2019). Women-centred abortion care: Legitimising a disenfranchised aspect of healthcare [Editorial]. Nursing Praxis in New Zealand, 35(2), 4-6. midwives as given. But when it comes to women's rights to termination of pregnancy, we are often not so sure. Primary health providers currently lack a clear and shared vision of what termination of pregnancy care should look like; where exactly it should be positioned in health services; who is best to provide services; and what the provider skill sets should be, resulting in access inequities (Doran \& Nancarrow, 2015). Historically and through to the present, abortion care is predominantly a siloed activity, on the periphery of other sexual and reproductive health services. This marginalised position underscores abortion as a stigmatised activity that has never been fully enfranchised as a legitimate aspect of women's health (Hoggart, 2017).

With the likely revisions to abortion law, including its removal from the Crimes Act 1961, opportunities now exist to reframe how we provide termination services and related sexual and reproductive health services. Of note, the United Nations Human Rights Council's third Universal Periodic Review of New Zealand (2019) emphasised the importance of removing abortion from the Crimes Act and instead making abortion access a human rights issue. In October 2018 the Law Commission submitted a briefing paper to Justice Minister Andrew Little, outlining recommendations on abortion law reform. 


\section{Nursing Praxis in New Zealand}

Politicians are likely to have a conscience vote on these recommendations at some time in 2019.

Although the authors support law reform, we believe that reform alone will not transform extant abortion services into holistic, women-centred care. We argue that women are best served when women's reproductive and sexual health services are amalgamated and offered in one facility by health providers with the requisite skill sets to cover the range of sexual and reproductive health needs with which women present. Nurses and midwives are well positioned to be central in the team designing the healthcare system to provide for women who want to consider or request termination of pregnancy. The services we design should enable the predominantly well women to have easy access; useful and supportive engagement; timely service and immediate access to long-acting contraception to assist women in getting on with their lives safely.

For more than 40 years New Zealand women have had to seek help for unplanned pregnancy in an environment of secrecy and isolation. Every woman requesting an abortion must present herself to two certifying consultants to ensure she meets the legal grounds for abortion; a serious risk to her physical or mental health. Not surprisingly, the majority of women have the abortion certified on mental health grounds. The compulsory 'tick box' nature of these conversations and criteria mean that women and providers are not well positioned to explore the moral ambiguity and ambivalence that may accompany a decision-making process.

Ironically, practitioners themselves who support women's rights to abortion may inadvertently cultivate an abortion discourse that presents a binary to women; minimising moral deliberation about foetal life and instead only focusing on the personal issues of autonomy and self-determination (Manninen, 2013). This binarised position can unintentionally mean that providers subtly alienate women, downplaying the diverse meanings that pregnancy holds for women (Altshuler, OjanenGoldsmith, Blumenthal, \& Freedman, 2017). We consider ourselves positioned with a pro-voice approach that affirms women's choice and also holds that for many women, a foetus is 'not nothing'. This pro-voice position is compatible with the authors' clinical practice experience companioning women and concurs with the literature pertaining to women's experiences; that even when women choose abortion, they commonly engage in moral deliberation over the life of the foetus. From a provoice orientation we consider that women-centred care means practitioners are able to have nuanced conversations with women that can accommodate this in-between space, rather than to assume that abortion is an amoral decision only about women's rights. Even if the latter is the practitioner's position, in order to provide holistic, culturally safe care to women, we consider that openness to a both/and position enables practitioners to be open to all women's stories.

Talking about abortion is not a regular conversation topic clinically. A commonplace debate in abortion care is the argument of whether or not counselling should be provided (Hoggart, 2015). Although we value the option of formal counselling we contend that holistic dialogue is possible and desirable in a single consultation. We consider it problematic to routinely split biomedical and psychological care and argue that all women's health service providers, excluding those who conscientiously object, should have the fundamental communication skills to explore with women the social, emotional and spiritual dimensions of her deliberation, as well as to discuss clinical matters.

Culturally competent care means listening to women. For example, Māori women who seek abortion may occupy an in-between place that falls outside of the anti/pro-abortion binary. Culturally there is the belief that the foetus has 


\section{Nursing Praxis in New Zealand}

wairua before birth, is whakapapa and is considered a taonga, and yet women may choose to abort to protect this life from the challenging contexts of their current lives (Le Grice \& Braun, 2017). Drawing from a holistic framework of care for all women, such as te whare tapa whā, means that providers' care is constituted in materially different ways from the current biomedical model in most settings. Additionally, Kitson's Fundamentals of Care Framework provides a multi-layered model to address systemic and policy levels of care as well as the relational (Kitson, Conroy, Wengstrom, Profetto-McGrath, \& Robertson-Malt, 2010).

Women want practitioners who are able to tailor their care; who are helpers, not directors; who meet women with high regard, and affirm that each woman is best placed to make the decisions about her sexual and reproductive healthcare. We are facilitators; with the connections and the means to expedite assistance from other providers should this additional care be required, including ensuring that systemic failures in contraception accessibility are addressed. We propose that a vital threshold of care is to cultivate a provoice space that may enable women to engage in a conversation that privileges women's own reflections about their pregnancy. This opportunity to put words to experience is likely to enhance women's post-abortion wellbeing. Therefore, healthcare consultations have an important role, as a compassionate and safe opportunity for women to investigate their options. Ideally, we work with the woman to see the size of the problem that led her to the termination of pregnancy request and help her to assess her resources to negotiate her immediate and future life. This is a pivotal time to incorporate abortion services into holistic models of care; to construct something enduring for women, a pro-voice stance that enables greater control of their sexual and reproductive lives and that sets us, in Aotearoa New Zealand, on a real path to gender equity.

\section{References}

Altshuler, A., Ojanen-Goldsmith, A., Blumenthal, P., \& Freedman, L. (2017). A good abortion experience: A qualitative exploration of women's needs and preferences in clinical care. Social Science \& Medicine, 191, 109-116. doi: 10.1016/j.socscimed.2017.09.010

Doran, F., \& Nancarrow, S. (2015). Barriers and facilitators of access to first-trimester abortion services for women in the developed world: A systematic review. Journal of Family Planning and Reproductive Health Care, 41(3), 170-180. doi: 10.1136/jfprhc-2013-100862

Hoggart, L. (2015). Abortion counselling in Britain: Understanding the controversy. Sociology Compass, 9(5), 365-378. doi: 10.1111/ soc4.12256

Hoggart, L. (2017). Internalised abortion stigma: Young women's strategies for resistance and rejection. Feminism \& Psychology, 27(2), 186-202. doi: 10.1177/0959353517698997

Kitson, A., Conroy, T., Wengstrom, Y., Profetto-McGrath, J., \& Robertson-Malt, S. (2010). Defining the fundamentals of care. International Journal of Nursing Practice, 16(4), 423. doi: 10.1111/j.1440-172X.2010.01861.x

Law Commission. (2018). Alternative approaches to abortion law. Retrieved from https://www.lawcom.govt.nz/abortion

Le Grice, J., \& Braun, V. (2017). Indigenous (Māori) perspectives on abortion in New Zealand. Feminism \& Psychology, $27(2), 144-162$. doi: 10.1177/0959353517701491

Manninen, B. (2013). The value of choice and the choice to value: Expanding the discussion about fetal life within prochoice advocacy. Hypatia, 28(3), 663-683. doi: 10.1111/j.1527-2001.2012.01302.x

Rook, H. (2018). Speaking up: The voice of New Zealand nursing [Editorial]. Nursing Praxis in New Zealand, 34(2), 4-5.

United Nations Human Rights Council. (2019). United Nations Periodic Review. Retrieved from https://www.ohchr.org/EN/HRBodies/ UPR/Pages/UPRMain.aspx 